\title{
Hematopoietic stem cell fate is established by the Notch-Runx pathway
}

\author{
Caroline Erter Burns, ${ }^{1}$ David Traver, ${ }^{2}$ Elizabeth Mayhall, ${ }^{1}$ Jennifer L. Shepard, ${ }^{1}$ \\ and Leonard I. Zon ${ }^{1,3}$ \\ ${ }^{1}$ Stem Cell Program and Division of Hematology/Oncology Children's Hospital and Dana Farber Cancer Institute, Howard \\ Hughes Medical Institute, Harvard Stem Cell Institute, Harvard Medical School, Boston, Massachusetts 02115, USA; \\ ${ }^{2}$ Section of Cell and Developmental Biology, University of California, San Diego, La Jolla, California 92093-0380, USA
}

\begin{abstract}
Identifying the molecular pathways regulating hematopoietic stem cell (HSC) specification, self-renewal, and expansion remains a fundamental goal of both basic and clinical biology. Here, we analyzed the effects of Notch signaling on HSC number during zebrafish development and adulthood, defining a critical pathway for stem cell specification. The Notch signaling mutant mind bomb displays normal embryonic hematopoiesis but fails to specify adult HSCs. Surprisingly, transient Notch activation during embryogenesis via an inducible transgenic system led to a Runx1-dependent expansion of HSCs in the aorta-gonad-mesonephros (AGM) region. In irradiated adults, Notch activity induced runx1 gene expression and increased multilineage hematopoietic precursor cells approximately threefold in the marrow. This increase was followed by the accelerated recovery of all the mature blood cell lineages. These data define the Notch-Runx pathway as critical for the developmental specification of HSC fate and the subsequent homeostasis of HSC number, thus providing a mechanism for amplifying stem cells in vivo.
\end{abstract}

[Keywords: Stem cell; Notch; Runx; AGM; zebrafish; irradiation]

Supplemental material is available at http://www.genesdev.org.

Received May 25, 2005; revised version accepted July 25, 2005.

In vertebrates, the adult hematopoietic system is composed of distinct cell lineages that undergo progressive differentiation from multipotent hematopoietic stem cells (HSCs) (Durand and Dzierzak 2005). The clinical importance of HSCs in transplantation protocols raises the significance of understanding their anatomical origin and fate potential. Hematopoiesis arises during two embryonic phases: a brief primitive wave that predominantly generates erythrocytes, followed by a definitive wave that produces long-term hematopoietic stem cells (LT-HSCs) capable of reconstituting the blood system for life. Definitive hematopoiesis occurs, at least in part, in the aorta-gonad-mesonephros (AGM) region, where LT-HSCs are associated with the ventral aortic wall. Although much is known about the cellular and functional properties of HSCs in mammals, relatively little is understood about the genetic pathways regulating their induction, expansion, and homeostasis during embryogenesis and adulthood. One pathway known to play a fundamental role in regulating a variety of cell fate decisions in progenitors of various organ systems is the Notch signaling pathway.

notch encodes a single pass glycoprotein receptor that

${ }^{3}$ Corresponding author.

E-MAIL zon@enders.tch.harvard.edu; FAX (617) 730-0222.

Article published online ahead of print. Article and publication date are at http://www.genesdev.org/cgi/doi/10.1101/gad.1337005. binds integral membrane ligands (Delta and Jagged) to transmit signals between cells in direct contact. Juxtacrine signaling generally occurs between neighbors that arise from a common precursor and share similar developmental potential (Lewis 1998). Notch is best known for its role in a process termed "lateral inhibition," a model explaining how one cell is selected from a group of equivalent precursors to adopt an alternative fate (Greenwald and Rubin 1992). In this scenario, activation of the Notch receptor in a particular cell inhibits ligand production by that cell (the "signal-receiving cell"). Concomitantly, cells producing high levels of ligand (the "signal-emitting cell") force their neighbors to activate Notch and produce less ligand. Lateral inhibition through the Notch pathway modulates lineage decisions in related cells by inhibiting one fate and promoting another (Bray 1998; Lewis 1998).

The mechanism by which Notch determines cell fate has been studied extensively in a variety of organisms and has led to the following model in which the Notch receptor undergoes three successive cleavage events to become active. Notch is first processed in the Golgi network to produce a functional transmembrane receptor. Once bound to its ligand, the second cleavage event occurs, which generates two products, the Notch extracellular domain (NECD) and a membrane-bound activated form (NEXT). The final cleavage event, mediated by presenilin-dependent $\gamma$ secretase activity, occurs 
within the NEXT fragment and results in the release of the Notch intracellular domain (NICD), which translocates to the nucleus and acts as a transcriptional regulator (Le Borgne and Schweisguth 2003).

Post-translational modification, specifically by addition of ubiquitin peptides, plays a critical role in regulating Notch-Delta activity (Lai 2002b). Drosophila neuralized was shown to encode an E3 ligase that ubiquitylates and promotes the endocytosis of the Notch ligand Delta (Deblandre et al. 2001; Lai et al. 2001; Pavlopoulos et al. 2001; Yeh et al. 2001). In vertebrate systems, however, Neuralized is not essential for lateral inhibition, suggesting that other E3 ligases may modify Delta. mind bomb, a neurogenic mutant isolated in several zebrafish mutagenesis screens (Haffter et al. 1996; Schier et al. 1996; Golling et al. 2002), encodes a highly conserved and previously uncharacterized E3 ligase that functions similarly to Neuralized (Itoh et al. 2003; Chen and Casey Corliss 2004). Mind bomb is required cell nonautonomously for Notch signaling and lateral inhibition by controlling Delta protein trafficking (Itoh et al. 2003; Chen and Casey Corliss 2004).

Notch receptors and their ligands are expressed in hematopoietic cells and have been implicated in regulating HSC induction and lineage cell fate decisions (Ohishi et al. 2003). In murine cell culture, constitutive Notch1 expression in hematopoietic progenitor and stem cells established immortalized cell lines able to generate progeny with either lymphoid or myeloid characteristics both in vitro and in long-term mouse reconstitution assays (Varnum-Finney et al. 2000, 2003). Retroviral activation of Notch1 in recombination activating gene-1 (RAG-1)-deficient mouse stem cells resulted in an increase of HSCs due to decreased differentiation in vivo (Stier et al. 2002). Similar results were observed when overexpressing the Notch effector gene HES-1 in cell lines (Kunisato et al. 2003). Increased numbers of Notch1-expressing HSCs were documented in mice with expanded osteoblastic niche cells that present Notch ligands in the bone marrow microenvironment (Calvi et al. 2003). More recently, the Notch signaling pathway was shown to be active in native adult HSCs and downregulated in differentiating progeny (Duncan et al. 2005). Taken together, activation of Notch in marrow-derived HSCs is likely important in maintaining HSC fate and may confer a survival advantage following transplantation by promoting stem cell self-renewal.

Loss of Notch signaling in mice and flies has demonstrated that this pathway is required for HSC induction during embryogenesis. When the AGM region was sur-

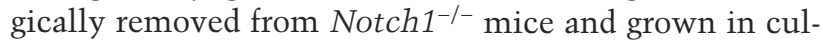
ture, AGM-derived cells were unable to produce colony forming cell (CFC) units in vitro or reconstitute the blood system of irradiated adult mice (Kumano et al. 2003). In Drosophila blood cell development, cardiogenic mesoderm is induced and subsequently segregated into vascular (cardioblasts), excretory (nephrocytes), or blood (lymph gland) specific tissues. Consistent with the mouse mutant, loss of Notch signaling caused a marked decrease of excretory and blood progeny with a concomi- tant expansion of vascular fates (Mandal et al. 2004). These results indicate that Notch signaling is important in the early generation of blood precursors across widely divergent phyla. The downstream target genes of Notch signaling in stem cells, however, remain to be determined.

Here, we used classic genetic experiments to reveal a hierarchical molecular network leading to the induction and expansion of hematopoietic stem and progenitor cells in the zebrafish embryo and adult. We show that the Notch signaling mutant mind bomb develops normal embryonic hematopoiesis but fails to specify definitive HSCs normally found associated with the ventral aortic wall. Using an inducible transgenic system, we found that brief Notch stimulation greatly expanded HSC number in the AGM. Morpholino knock-down of Runx1 function completely abolished this increase, showing for the first time that Runxl is a downstream effector of Notch signaling in HSC induction. In the adult, we examined the effect of activated Notch on marrow recovery following irradiation. Compared with control siblings, the percentage of multilineage hematopoietic precursors increased approximately threefold, followed by mature myeloid and lymphoid cells. The expanded precursor population showed transcriptional up-regulation of the runx1, 1mo2, and scl genes, all markers of stem and progenitor cells. These findings define the Notch-Runx pathway as critical during both embryogenesis and adulthood to maintain HSC homeostasis.

\section{Results}

Mind bomb, the ubiquitin ligase for Notch ligands, is required for HSC specification

To assess the requirement for the Notch pathway in definitive HSC induction, a null allele of the Notch signaling mutant mind bomb (mib) was analyzed. Both $c-m y b$ and runx 1 transcripts mark emerging definitive hematopoietic stem and progenitor cells that are normally confined to the ventral wall of the zebrafish dorsal aorta (Burns et al. 2002; Traver and Zon 2002; Gering and Patient 2005). mind bomb mutants lack aortic $c$-myb and runx1 expression (Fig. 1d,e) compared with wild-type siblings (Fig. 1a,b). Moreover, rag-1 transcripts expressed by differentiated thymic T-cells (Fig. 1c) are absent in mind bomb embryos $4 \mathrm{~d}$ post-fertilization (dpf) (Fig. 1f). To exclude the possibility that HSC induction was defective because a dorsal aorta was not specified, we analyzed flk 1 expression in mind bomb animals. flk 1 transcripts appear relatively normal in mind bomb mutants (Fig. 1j) compared with wild-type animals (Fig. 1g), although intersomitic vessels are somewhat disorganized. The presence of a dorsal aorta with concomitant loss of HSC/ progenitor cells and lymphoid progeny suggests that Notch signaling is required for definitive HSC specification.

We next analyzed whether Notch signaling is required for primitive hematopoiesis. Blood and endothelial markers scl, gata1, fli1, and runx1 are expressed at the 


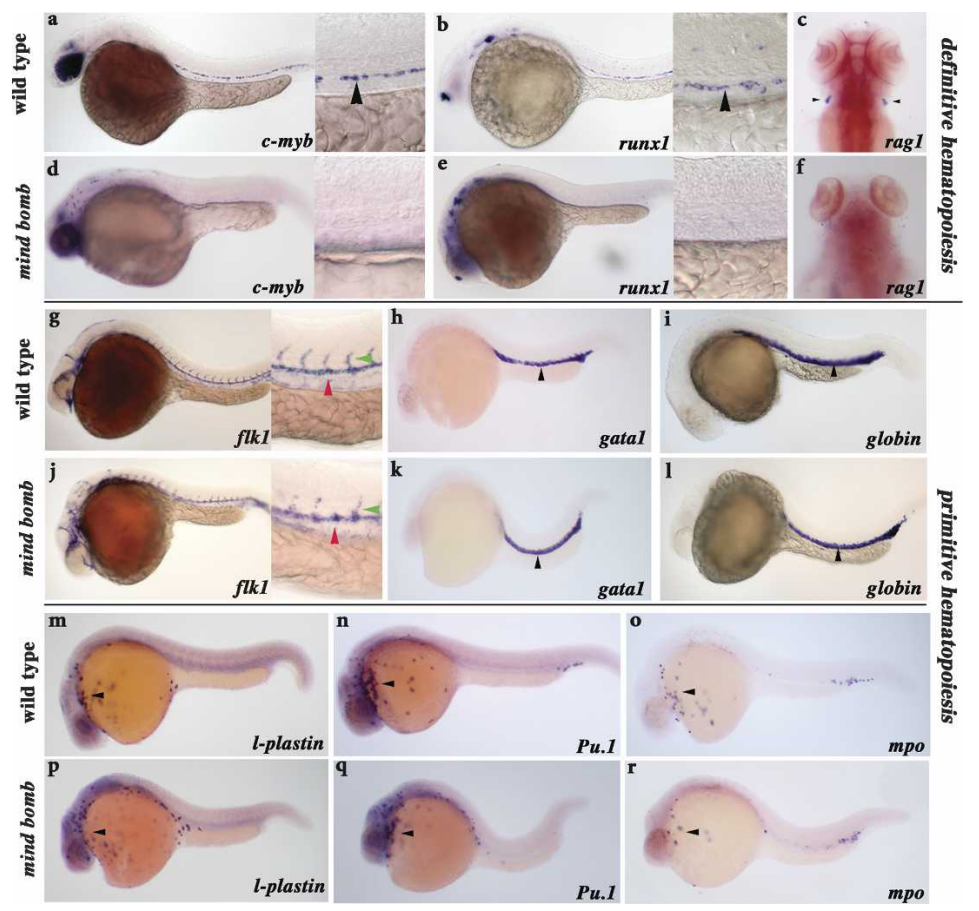

Figure 1. Mind bomb is required for definitive HSC specification, but is dispensable for primitive hematopoiesis. Whole-mount in situ hybridization was performed on wild-type and mind bomb embryos. Genotype is indicated prior to each row, and the probe used is listed in each panel. $(a, b, d, e)$ Lateral view, $36 \mathrm{hpf}$. Low magnification (10x) and higher magnification (40x) of the trunk region. HSC expression is indicated by arrowheads in $a$ and $b .(c, f)$ Dorsal view, 4 dpf. Bilateral rag-1 expression in thymi is indicated by arrowheads in c. $(g-r)$ Lateral view, 28 hpf. $(g, j)$ Low magnification $(10 \times)$ and higher magnification $(40 \times)$ of the trunk region. Aortic expression is indicated by red arrowheads; intersomitic vessels are indicated by green arrowheads. (h-1) Black arrowheads indicate the embryonic red cell in the ICM. $(m-r)$ Black arrowheads indicate spotted expression in primitive myeloid cells. 10-somite stage in all embryos derived from incrossing mind bomb heterozygous adults (data not shown), suggesting that Notch signaling is dispensable for primitive progenitor cell induction. Primitive erythrocyte numbers appear normal in the intercellular mass (ICM) of 24 $\mathrm{h}$ post-fertilization (hpf) mind bomb mutants compared with wild-type siblings as seen by gata1 (Fig. 1k,h), globin (Fig. 11,i), and scl (data not shown) expression. Primitive myeloid cells, marked by 1-plastin (Fig. 1m,p), Pu.1 (Fig. 1n,q), and myeloperoxidase (mpo) (Fig. 1o,r) are also detected in mind bomb embryos at levels similar to that seen in wild type. Our results suggest that Notch signaling is dispensable for primitive hematopoiesis, but necessary for the definitive hematopoietic wave.

\section{Notch signaling is sufficient for definitive HSC induction in the embryonic AGM}

Given the requirement of Notch signaling for blood stem cell induction and the need to find agents that increase stem cell number, we evaluated whether Notch activity was sufficient to generate more HSCs in vivo. Since injection of an activated form of notch (NICD) mRNA is known to cause severe dorso-anterior defects (Lawson et al. 2001), we made use of a powerful resource in zebrafish to temporally regulate NICD activation using a Gal4/ UAS transgenic system (Scheer and Campos-Ortega 1999; Scheer et al. 2002). Two major advantages of this approach are that NICD can be induced at any given time point and that the activation can be brief. Since constitutive Notch activity is known to block differentiation of stem cells both in vitro and in vivo, this system is unique in that NICD induction is reversible and does not prevent lineage commitment.
Adults carrying the yeast transactivator Gal4 under the control of the zebrafish heat-shock promoter (hsp70:gal4) (Scheer and Campos-Ortega 1999; Halloran et al. 2000) were crossed to animals hemizygous for the Gal4-responsive upstream activating sequence (uas) driving the zebrafish notch1a intracellular domain (uas:NICD) (Scheer and Campos-Ortega 1999). During mid-somitogenesis, embryos were heat-shocked (see Materials and Methods), raised until 36-40 hpf, and then fixed and processed for in situ hybridization. Whole-mount and section analyses indicated that while control siblings showed ventrally restricted aortic $c-m y b(n>200 ; 100 \%)$ and runx1 (n>150; 100\%) expression (Fig. 2a,c,e,f), hsp70:gal4;uas:NICD embryos displayed ectopic transcripts throughout the aortic roof and vein $(c-m y b$, $n=52 / 60$; runx $1, n=51 / 54$ ) (Fig. 2b,d,g,h). Since HSC expansion could be influenced by the cell cycle, induced 24-hpf and 40-hpf hsp70:gal4;uas:NICD and control sibling embryos were immuno-stained for the phosphorylated form of histone $\mathrm{H} 3$ (28 hpf [data not shown]; 40 hpf [Fig. 2i,j]) to mark cells in mitosis or for BrdU incorporation to distinguish cells undergoing DNA synthesis (28 hpf [data not shown]; 40 hpf [Fig. 2k,1]). At all time points analyzed, no significant difference in the number of dividing cells between hsp70:gal4;uas:NICD and control embryos could be visualized, demonstrating that stem cell expansion is not due to increased proliferation. Collectively, these data show that Notch activation is capable of expanding definitive HSCs during development and demonstrate that the aortic roof and vein are competent to express HSC markers in vivo.

NICD may be capable of expanding both primitive and definitive hematopoietic progenitors, or may be 


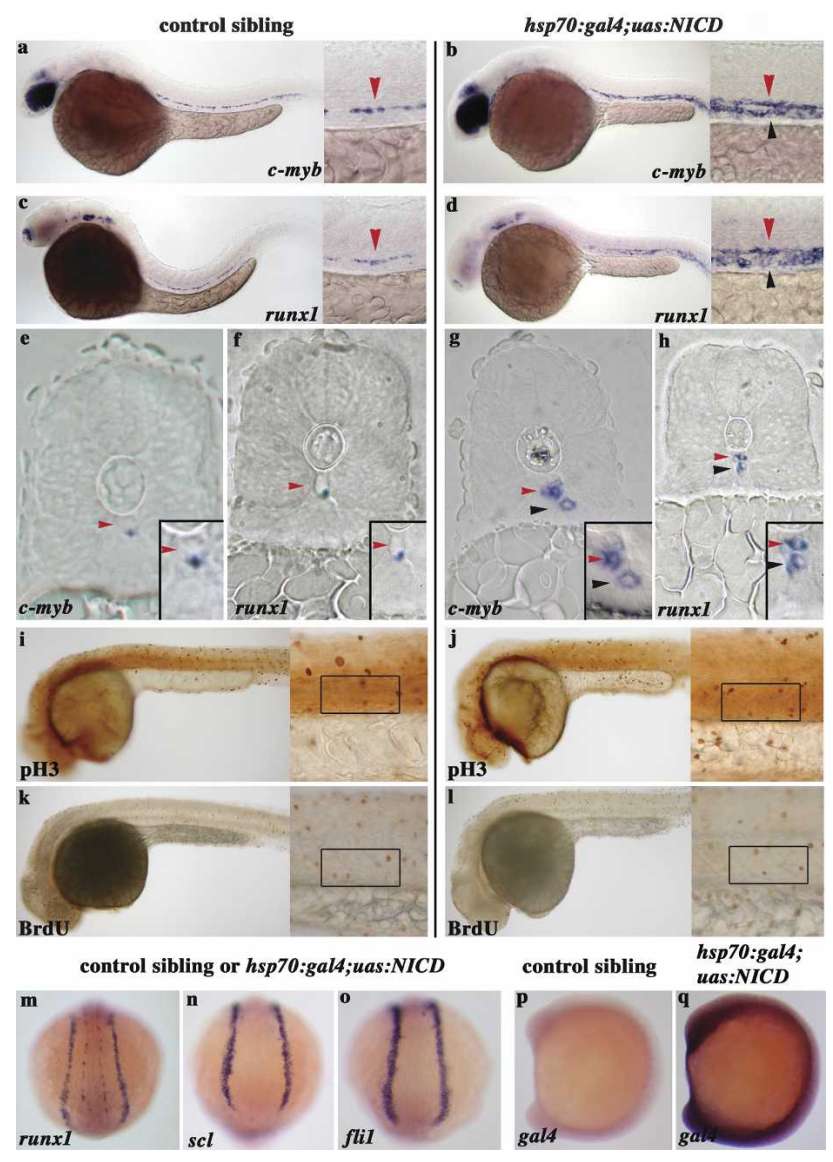

Figure 2. NICD expands HSC/progenitor cells in the AGM. Whole-mount in situ hybridization was performed on control sibling and hsp70:gal4;uas:NICD embryos (see Materials and Methods for heat-shock conditions). Red arrowheads denote aorta expression, and black arrowheads show vein expression. The probe used is listed in each panel. $(a-d)$ Lateral view. Low magnification $(10 x)$ and higher magnification $(40 x)$ of the trunk region. hsp70:gal4;uas:NICD transgenics show expanded HSC markers throughout the artery and vein. $(e-h)$ Plastic sections through the trunk region of 36-40 hpf whole-mount in situ hybridized embryos. $(e, f)$ Note ventrally restricted $c$-myb and runx 1 aortic expression. $(g, h)$ Note ectopic expansion of $c$-myb and runx 1 to the aortic roof and vein. $\mathrm{pH} 3$ immunostaining at $\sim 40 \mathrm{hpf}(i, j)$ (see Materials and Methods) and BrdU incorporation at $\sim 40$ hpf $(k, l)$. Compare brown stain in dividing cells in vessel region of wild-type $(i, k)$ to hsp70:gal4;uas:NICD $(j, 1)$. $(m-q)$ Approximately $10-12$ somite stage. $(m-o)$ Dorsal view; $(p, q)$ lateral view.

exclusive for increasing adult HSCs. Primitive progenitor markers runx1, scl, and fli1 were examined $3.5 \mathrm{~h}$ post-heat shock and were not expanded (Fig. $2 \mathrm{~m}-\mathrm{O}$ ). Induced Notch is active at this time since NICD RNA is detected in embryos as early as $1.5 \mathrm{~h}$ postheat shock (Scheer et al. 2002). In our hands, gal4 RNA was highly expressed in hsp70:gal4 transgenic animals (Fig. 2q) and was absent from control siblings (Fig. 2p). Therefore, Notch-dependent expansion of HSCs in the AGM is independent of primitive progenitor cell induction.

\section{Dose-dependent HSC/progenitor cell expansion is independent of artery identity}

HSC induction could be dependent on arterial fate decisions. Work by Lawson and Weinstein (Lawson et al. 2001) clearly show that Notch signaling is partially required for artery identity in that mind bomb mutants fail to express the arterial markers ephrinb2a and notch3, but maintain arterial expression of $t b x 20, f 1 k 1$, and gridlock. Although it was initially determined that NICD was not sufficient to expand aortic-specific markers to the vein (Lawson et al. 2001), expansion of ephrinb2a was later demonstrated (Lawson et al. 2002). These studies suggest that Notch signaling is required in the zebrafish for some aspects of artery identity and is sufficient to expand some arterial markers to the vein.

We tested whether the abnormal expansion of HSCs to the vein correlated with a conversion of vein to artery identity. Embryos from hsp70:gal4 and uas:NICD matings were heat-shocked for varying lengths of time and processed by in situ hybridization for ephrinb2a or runx1 at $28 \mathrm{hpf}$ or $c-m y b$ at $40 \mathrm{hpf}$. When heat-shocked for 1 min, we detected no expansion of $c$-myb $(n=0 / 19)$ or ephrinb2a $(n=0 / 27)$ transcripts in hsp70:gal4;uas:NICD transgenics (Fig. 3a,c). Weak expansion of runx1 was detectable in the vein $(n=2 / 9)$ (Fig. 3b), although most hsp70:gal4;uas:NICD embryos showed no ectopic transcripts. After 10 min of heat shock, hsp70:gal4;uas:NICD embryos showed considerable expansion of $c-m y b$ $(n=26 / 32)$ and runx1 $(n=4 / 8)$ expression throughout the artery and in some regions of the vein, but no expansion of ephrinb2a $(n=0 / 18)$ could be visualized (Fig. $3 \mathrm{~d}-\mathrm{f})$. If embryos were exposed to heat for $20 \mathrm{~min}, c-m y b(n=36 /$ $36)$ and runx1 $(n=10 / 10)$ transcripts were hugely expanded in the aorta and vein of hsp70:gal4;uas:NICD transgenics, suggesting that ectopic HSCs had been induced (Fig. 3g,h). Conversely, no hsp70:gal4;uas:NICD embryos showed significant expansion of ephrinb2a expression $(n=0 / 39)$ (Fig. 3i). These data demonstrate that artery identity and HSC specification can be uncoupled in vivo, suggesting that Notch signaling acts through separate pathways to regulate induction of each cell fate. Additionally, these studies establish a dose response for Notch signaling in the derivation of HSCs.

\section{Runx1 is dispensable for artery identity in vivo}

In the mouse, Runx1 is dispensable for primitive hematopoiesis, but necessary for the definitive wave (Wang et al. 1996; Fujita et al. 2001; Okuda et al. 2001). More recently, morpholino knock-down experiments (Ekker 2000) revealed a similar function for Runxl in the developing zebrafish embryo (Kalev-Zylinska et al. 2002). As the hematopoietic phenotype displayed by the runx1 morphant is strikingly similar to mind bomb, we hypothesized that these pathways may converge at the level of definitive HSC induction.

To define a genetic relationship between notch signaling and runx1, we established a runx1 morphant pheno- 


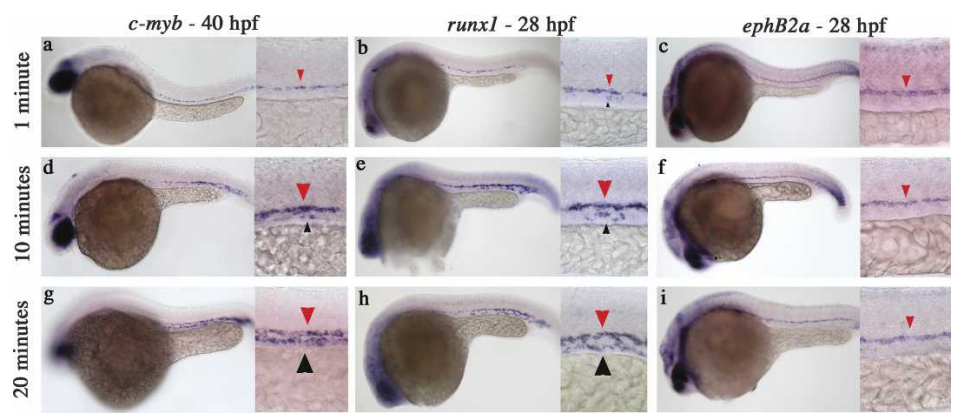

Figure 3. NICD dose-dependently expands HSCs independent of aortic cell fate. Whole-mount in situ hybridization was performed on hsp70:gal4;uas:NICD embryos heat-shocked at $40^{\circ} \mathrm{C}$ for 1,10 , or $20 \mathrm{~min}$. Red arrowheads denote aorta expression, and black arrowheads show vein expression. The arrowhead size suggests the level of transcript present. Low magnification $(10 \times)$ and higher magnification $(40 x)$ of the trunk region. $(a, d, g) c$-myb HSC expression. $(b, e, h)$ runx1 HSC expression. $(c, f, i)$ ephrinB2a arterial expression. type by coinjecting two morpholinos that block mRNA splicing (see Materials and Methods). As in previously published reports (Kalev-Zylinska et al. 2002; Gering and Patient 2005), we found that Runxl is dispensable for primitive hematopoiesis but required for $c-m y b$ expressing definitive HSCs (Supplementary Fig. 1a). RT-PCR analysis demonstrated that runxMO injection abolished normal runx1 transcripts compared with uninjected controls (Supplementary Fig. 1b). We next investigated vessel integrity and aortic identity by analyzing expression of the aortic markers notch3, deltaC, and ephrinb2a in runx morphant animals. One of the hallmarks of proper aorta identity is the formation of branching intersomitic vessels (ISV). Although aortic identity is not completely normal in runx morphants, as seen by the lack of fli1 (Fig. 4a,b) $(n=19)$ and flk1 (Fig. 4c,d) $(n=23)$ expressing ISVs, notch3 $(n=13)$, deltaC $(n=14)$, and ephbrinb2a $(n=12)$ aortic expression is maintained in the absence of Runx1 function (Fig. 4e-j). These data show that Runx1 is dispensable for proper localization of aortic transcripts, suggesting that Runxl function is not required for most aspects of artery identity.

We next tested whether $c$-myb-expressing HSCs could be expanded or rescued by overexpression of runx1 RNA in wild-type, runx1 morphant, or mind bomb mutant animals (Fig. 5). runx1 RNA was injected at the 1-2-cell stage, and embryos were raised until $\sim 40 \mathrm{hpf}$. Compared with uninjected sibling controls that show ventrally restricted aortic $c-m y b$ expression (Figs. 2e, 5a), runx1 mRNA expanded $c$-myb-expressing HSCs ectopically throughout the aortic roof and vein ( $n=16 / 24)$ (Fig. 5b). Interestingly, runx1 mRNA overexpression partially rescued $c$-myb-expressing HSCs in the aortic floor of runx1 morphants $(n=20 / 24)$ (cf. Supplementary Figs. 1d and $5 \mathrm{c})$ and mind bomb animals $(n=8 / 10)$ (cf. Figs. $1 \mathrm{~d}$ and $5 \mathrm{~d})$. We did notice that wild-type embryos injected with runx1 RNA showed greater numbers of $c$-myb-positive cells compared with runxMO- and mind bomb-injected animals, suggesting that the total amount of Runx1 function in the developing embryo is critical for HSC specification. In summary, our results demonstrate that runx1 functions genetically downstream of or in parallel to notch signaling and mind bomb. These data suggest that Runx1, like NICD, dose-dependently influences the number of $c$-myb-positive HSCs specified in the AGM.
Runx1 is required for NICD-dependent expansion of definitive HSCs in the AGM

During embryonic neurogenesis, Mind Bomb is known to act upstream of NICD production in the Notch signaling pathway (Itoh et al. 2003; Chen and Casey Corliss 2004). We tested whether NICD would suppress the mind bomb definitive HSC phenotype. A mind bombspecific morpholino (mibMO) (Itoh et al. 2003) was injected into embryo clutches derived from hsp70:gal4 and uas:NICD matings. Following exposure to heat shock, control siblings showed complete loss of both $c-m y b$ $(n=117 / 125)$ and runx1 $(n=97 / 141)$ transcripts (Fig. $5 \mathrm{e}, \mathrm{g})$ in the dorsal aorta, thereby phenocopying the mind bomb mutant. mibMO-injected hsp70:gal4;uas:NICD embryos showed the notch gain-of-function phenotype in that both $c$-myb $(n=45 / 45)$ and runx1 $(n=43 / 49)$ transcripts were expanded to the aortic roof and vein (Fig. 5f,h). These data show that the Mind Bomb E3 ubiquitin ligase functions upstream of NICD during HSC specification. To test whether runx1 is required for NICD-dependent expansion of HSCs in the AGM, the runxMO was injected into clutches derived from hsp70:gal4 and uas:NICD matings (Fig. 5i,j), and the animals were subsequently heat-shocked. Interestingly, runx morphant hsp70:gal4;uas:NICD transgenics (Fig. $5 j)$ showed low to no $c-m y b$ expression in the aortic floor $(n=9 / 12)$, thus phenocopying the runx morphant control siblings (Fig. 5i) $(n=30 / 37)$. This finding demonstrates that Runx1 is required for NICD-dependent HSC expansion. Together, these results suggest a genetic hierarchy leading to HSC induction in the AGM in which NICD is genetically downstream of mind bomb and upstream of runx1.

\section{NICD activation improves marrow recovery following irradiation}

Our studies in the embryo have demonstrated an important role for signaling via the Notch-Runx pathway in the initial specification of HSC fate. We next tested whether this pathway also plays a role in the adult hematopoietic system. We have previously shown that a sublethal dose of total body irradiation rapidly leads to a virtual depletion of hematopoietic cells in adult whole kidney marrow (Traver et al. 2004). Despite this pro- 


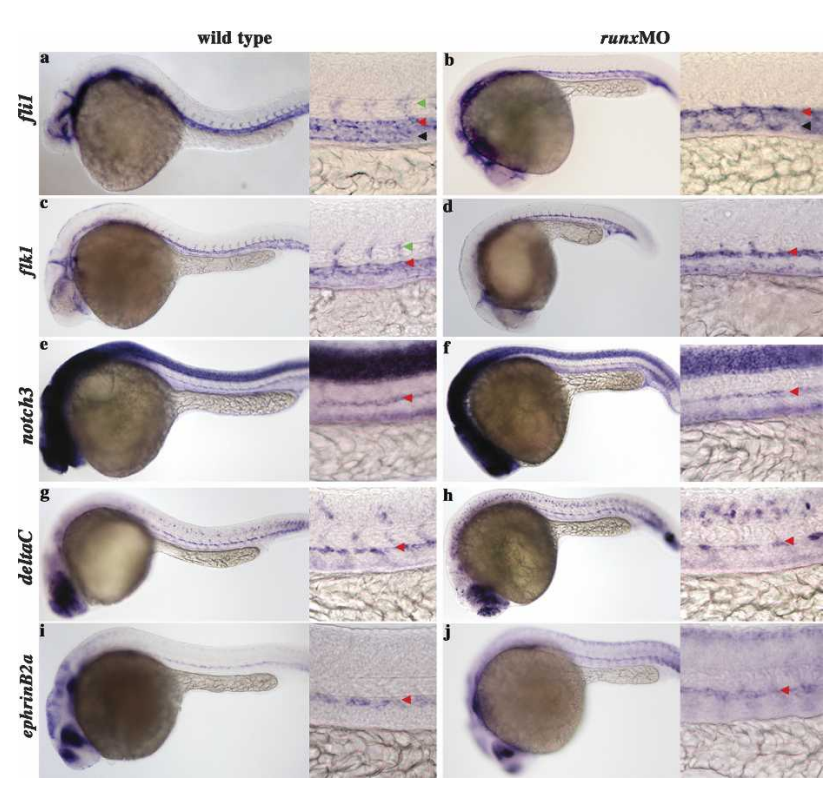

Figure 4. Runxl is dispensable for aortic cell fate. Wholemount in situ hybridization was performed on wild-type and runxMO-injected embryos at $\sim 28 \mathrm{hpf}$. Embryo manipulation is indicated above each column, and probes used are indicated to the left of each row. Lateral views. Low magnification $(10 x)$ and higher magnification $(40 x)$ of the trunk region. Red arrowheads denote aorta expression, black arrowheads show vein expression, and green arrowheads mark aortic intersomitic vessels. fli1 $(a, b)$ and $f 1 k 1(c, d)$ expression in wild-type and runxMOinjected embryos. Note lack of intersomitic vessels in runxMO animals. (e-j) notch3, deltaC, and ephrinb2a aortic expression is maintained in runxMO-injected animals. Loss of c-myb at 36 hpf served as a positive control for the runx morphant phenotype.

found cytopenia, all animals survive and show complete repopulation of the kidney within $1 \mathrm{mo}$, demonstrating that HSCs can survive this irradiation dose. Although limiting dilution assays are not yet available to test the number of transplantable HSCs in any given adult zebrafish, the recovery kinetics of the blood cell lineages are measurable by flow cytometry, thus allowing a functional HSC assay to be performed (Traver et al. 2003, 2004). To this end, we tested whether Notch induction following irradiation could speed multilineage hematopoietic cell repletion in the marrow compared with wildtype controls.

Control sibling or hsp70:gal4;uas:NICD transgenic (TG) adults were subjected to irradiation and then exposed to heat shock. We examined the recovery kinetics of all the blood lineages by FACS over a 1-mo time period (Fig. 6a,b). Prior to irradiation (day 0) or heatshock treatment (day 2), no significant differences in the precursor, myeloid, or lymphoid blood populations could be detected between the control sibling and hsp70:gal4;uas:NICD adults. On day 6 the hematopoietic precursors, which are the predecessors of each mature blood lineage (Traver et al. 2003), showed an 2.5-fold increase in the hsp70:gal4; uas:NICD animals compared with control siblings $16.3 \%$ and $2.6 \%$, respectively). By day 7, the percentage of precursors reached
$20.1 \%$ in the hsp70:gal4;uas:NICD transgenics compared with $6.5 \%$ in the wild-type adults. As shown in Figure $6 \mathrm{~b}$, the largest differences between groups over time were seen at days 6 and 7 in the precursor population, day 8 in the myeloid fraction (14\% TG vs. 7\% wild type), and day 14 in the lymphoid pool (18\% TG vs. 9\% wild type). By day 14, the difference in percentages of precursor and myeloid cells normalized between the two cohorts as each approached preirradiation population distributions. For the lymphoid fraction, stabilization occurred at day 30. These data show that a brief dose of activated Notch accelerates the recovery of the precursor pool, followed by the multiple blood lineages post-irradiation.

To visualize the cell types present on day 4 and day 7, cytospins from whole kidney marrow were performed (Fig. 6c). As predicted by the FACS analyses, no appreciable difference between control siblings and hsp70:gal4;uas:NICD transgenics could be seen on day 4 , a time at which the kidney blood lineages are disappearing due to irradiation. By day 7, however, hsp70:gal4;uas:NICD animals displayed more multilineage precursor cells, mainly of the myeloid and lym-
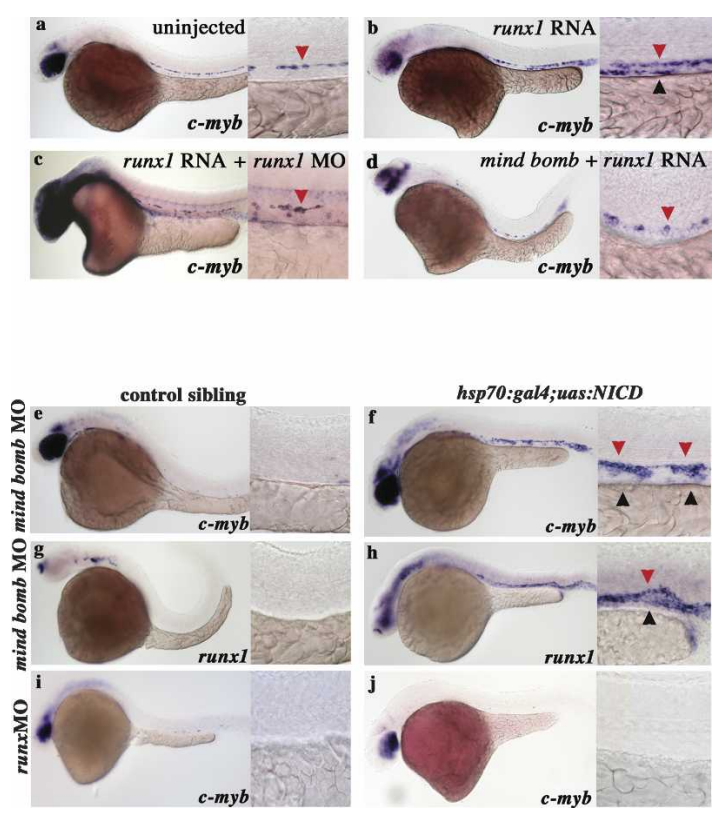

Figure 5. Runxl is required for NICD-dependent HSC expansion in the AGM. Whole-mount in situ hybridization on 36-40 hpf embryos. Embryo manipulation, genotype, and probes used are described for each panel. Red arrowheads show the artery, and black arrowheads highlight the vein. Lateral views. Low magnification (10x) and higher magnification $(40 \times)$ of the trunk region. Injection of $\sim 10 \mathrm{pg}$ of runx1 mRNA expands $c$-mybpositive HSCs in wild type (cf. $a$ and $b$ ), rescues HSCs in runx morphants (cf. Supplementary Figs. 1d and 5c), and rescues HSCs in mind bomb mutants (cf. Figs. $1 \mathrm{~d}$ and $d$ ). (e-j) mind bomb or runx morpholinos were injected into embryos derived from hsp70:gal4 and uas:NICD intercrosses. After heat shock (see Materials and Methods), injected embryos were hybridized with labeled c-myb or runx1 probes. The hsp70:gal4;uas:NICD HSC expansion phenotype is evident in the presence of mibMO $(e-h)$, but is absent in the presence of runxMO $(i, j)$. 


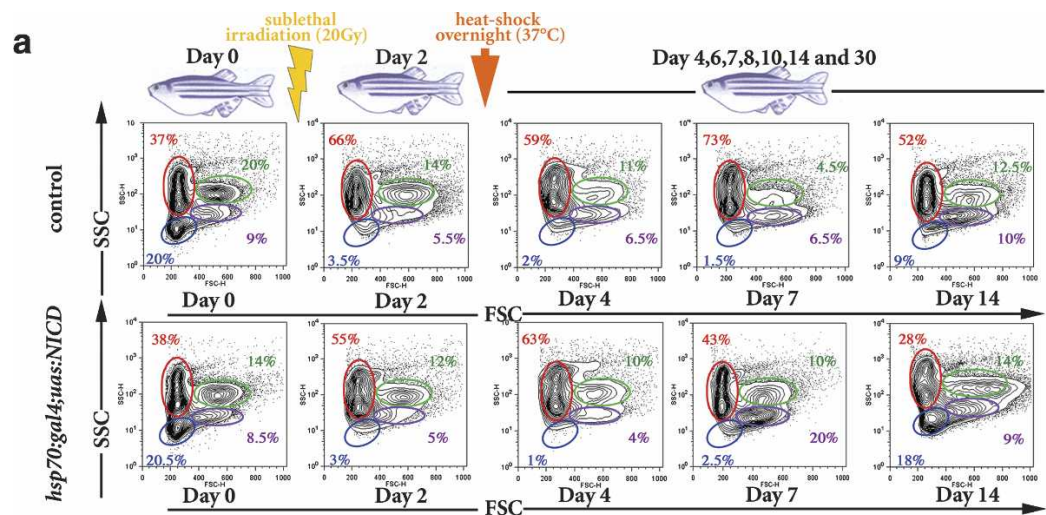

b
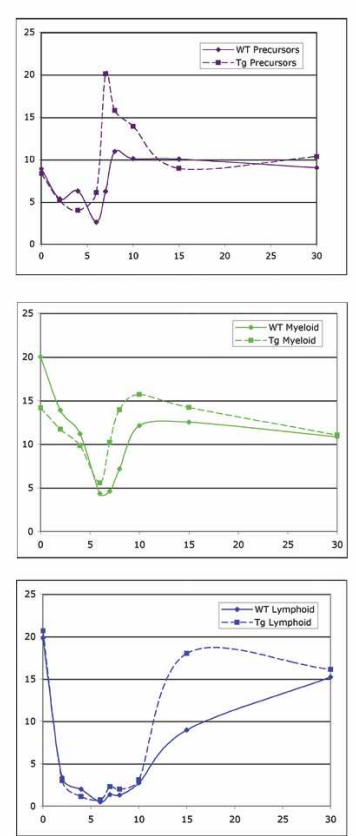

C

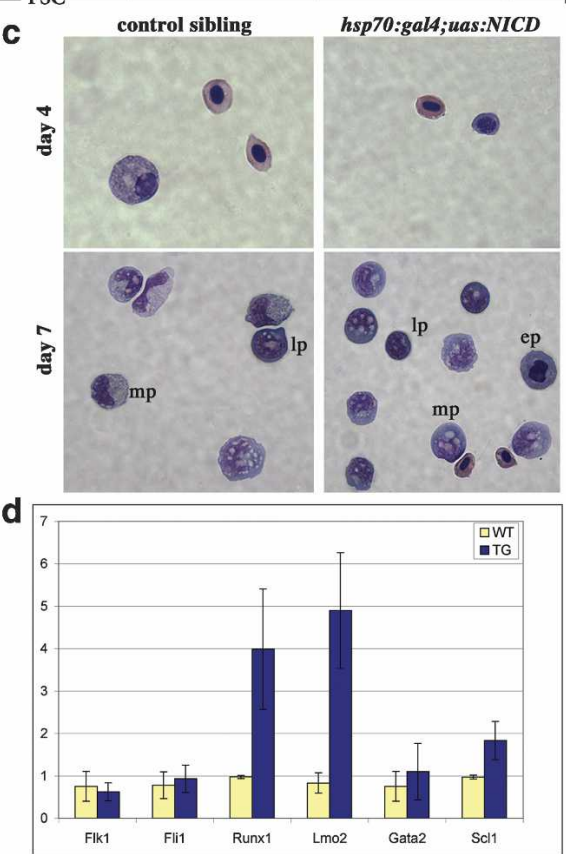

Figure 6. NICD expands the multilineage precursor cells in adult marrow and accelerates blood lineage recovery post-irradiation. (a) Cartoon depicting manipulation of adult control sibling or hsp70:gal4;uas:NICD fish is outlined. Light scatter profiles of whole kidney marrow from adult control sibling or hsp70:gal4;uas:NICD fish showing the effects of sublethal irradiation and heat shock on the relative percentages of erythrocytes (red gate), lymphocytes (blue gate), precursors (purple gate), and myelomonocytes (green gate) over time. Each FACS plot is of one representative fish from each time point, and the percentages reflect the average number of cells in each gate. The erythroid population is excluded from our analyses due to a marked variability in the numbers extracted from whole kidney dissections. This inconsistency has been previously reported (Traver et al. 2004) and is likely due to the close association of the kidney with the dorsal aorta. $(b)$ The average percentage of cells in each gate ( $Y$-axis, shown as percentages in $a)$, with the exception of erythroid, was plotted over time $(X$ axis). (c) Cytospin preparation of day 4 (top) or day 7 (bottom) whole kidney marrow from control sibling (left) or hsp70:gal4;uas:NICD adults (right). (d) Quantitative PCR analysis from control sibling or hsp70:gal4;uas:NICD whole kidney marrow on day 3 (see Materials and Methods). The average fold induction of each transcript is represented by the bar graph with standard deviations. (WT) Wild type; (TG) hsp70:gal4;uas:NICD; (lp) lymphocyte precursor; (ep) erythroid precursor; (mp) myeloid precursor. phoid lineages than their sibling controls. These findings demonstrate that NICD is capable of expanding early multilineage hematopoietic precursors at a rate faster than that of control siblings, strongly suggesting that Notch signaling is expanding a common predecessor.

Since precursor cells from multiple lineages were expanded in hsp70:gal4;uas:NICD animals on day 6, we analyzed whether transcripts of known stem and progenitor cell markers were transcriptionally up-regulated prior to the increase of the precursor population. RNA was harvested from individual control sibling or hsp70:gal4; uas:NICD kidneys on day 3 and quantitative PCR was performed. The fold change in gene expression was determined for each kidney and the average fold change for each gene of interest was calculated and graphed (Fig. 6d). While expression of flk1, fli1, and gata2 were not affected, runx 1 and $1 m o 2$ transcripts were four- and fivefold higher in the hsp70:gal4;uas:NICD animals, respectively, while $s c l$ transcripts were increased by twofold. These findings demonstrate that hsp70:gal4; uas:NICD adults up-regulate stem and progenitor cell markers in their marrow following heat- shock exposure, likely reflecting an expansion of the HSC pool as a result of NICD activity. Moreover, limited Notch signaling accelerates hematopoietic recovery without permanently altering the balance of cells in each blood lineage. Our findings show that the Notch pathway is used during both embryogenesis and adulthood to maintain proper stem cell homeostasis.

\section{Discussion}

Notch signaling has been hypothesized to control stem cell self-renewal. Prior experimental approaches have allowed only limited conclusions to be drawn since constitutive Notch activation, typically with a retrovirus, renders a maturation defect that prevents the normal differentiation of progenitors. Our data demonstrate that Notch activity is necessary to establish HSC fate and sufficient to expand HSC number in the embryonic AGM. In the adult, a brief pulse of Notch activity expands the HSC pool following sublethal doses of total body irradiation and speeds the recovery of multilineage hematopoiesis without permanently altering blood lin- 
eage homeostasis. We further identify runx1 as a major target of Notch signaling and demonstrate the requirement of the Notch-Runx pathway for stem cell fate.

\section{Notch and hematopoietic cell fate determination}

Hematopoietic cell fate decisions occur throughout embryogenesis and adulthood, many of which are controlled by the Notch signaling pathway. Notch1 influences the decision of $\mathrm{T}$ versus $\mathrm{B}$ lymphoid fate (Pui et al. 1999; Radtke et al. 1999|, lymphoid versus myeloid differentiation (Stier et al. 2002), $\alpha \beta$ versus $\gamma \delta$ T-cell fate (Washburn et al. 1997), and CD4 versus CD8 T-cell lineages (Robey et al. 1996), thus providing a key regulatory signal in determining the fate of multipotential hematopoietic precursors. Here, we provide evidence that Notch drives mesodermal progenitors to the HSC fate.

The process of Notch regulating stem cell fate appears to be evolutionarily conserved. In flies, Notch is required for specification of dorsal mesoderm to the blood, endothelial, and nephrocyte fates (Mandal et al. 2004). In the absence of Notch, the mesoderm adopts an entirely endothelial fate, while in the presence of high Notch activity, it becomes predominantly blood and nephrocytes. Although the hematopoietic system of a vertebrate is more elaborate and under distinct control mechanisms, our studies support the Drosophila conclusions and indicate a conservation of Notch driving the blood stem cell fate. Mice deficient for Notch1 activity (Kumano et al. 2003; Hadland et al. 2004) or one of its transcriptional mediators, RBPјк (Robert-Moreno et al. 2005), lack embryonic HSC specification in the AGM. Similarly, we found that mind bomb mutant embryos do not specify HSCs, establishing the Notch requirement during stem cell induction.

During vertebrate embryogenesis, mesoderm in the AGM region becomes specified to several fates. Many studies refer to the "hemogenic endothelial cell" as a bipotential precursor to the HSC and vascular tree; however, recent studies provide evidence for a subaortic mesenchymal cell population that independently migrates through the endothelial cells to become hematopoietic (Mendes et al. 2005). Additionally, the "mesoangioblast" has been proposed as a common mesodermal precursor to the blood, endothelial, mesenchymal, and smooth muscle lineages (Cossu and Bianco 2003; Ema et al. 2003). The fate decisions imposed on mesodermal progenitors within the AGM are clearly influenced by the Notch pathway. For instance, mice deficient in RВРјк show expanded VE-Cadherin and CD31/PECAM endothelial cell expression with concomitant loss of definitive HSCs (Robert-Moreno et al. 2005). Ablation of the COUP-TFII transcription factor in endothelial cells enabled veins to acquire arterial characteristics, including the expression of Notch 1 and the formation of ectopic HSCs (You et al. 2005). This result would favor Notch acting to induce HSCs from a hemogenic endothelial cell. Our results in zebrafish support a model in which the Notch pathway regulates arterial and HSC fate choice either from distinct mesodermal populations or over different developmental windows since each decision can be uncoupled in vivo. In support of this hypothesis, Notch activity did not expand arterial ephrinb2a expression to the vein, a location where the HSC transcripts $c-m y b$ and runx 1 were robust. In this case, HSCs could be specified from mesodermal precursors that are distinct from those committed to the arterial fate. It is possible that subaortic mesenchymal cells are a target of Notch activity and a source of HSC precursors independent of the endothelium. The finding that both aorta and vein express HSC markers in the Notch-activated state with minimal change in ephrinB2a expression indicates that Notch independently regulates mesoderm-HSC and artery-vein cell fate decisions.

Lateral inhibition has been proposed in the central nervous system whereby Notch signaling promotes nonneural fates while inhibiting neural development (Lewis 1998). HSC fate may be established by a similar mechanism whereby Notch activation in an endothelial or mesenchymal cell causes down-regulation of ligand production. Consequently, a cell that produces more ligand will force its neighbor to produce less, thus generating a salt-and-pepper pattern of cells containing elevated Notch activity. In this model, cells containing high levels of NICD would become HSCs, while those with low NICD activity would remain endothelial or mesenchymal.

\section{The Notch-Runx1 pathway participates in self-renewal in the stem cell niche}

The adult stem cell niche has been recently characterized in the mouse bone marrow and consists of an endosteal (quiescent) and vascular (proliferative) compartment (Heissig et al. 2002; Calvi et al. 2003; Zhang et al. 2003; Arai et al. 2004; Avecilla et al. 2004). Under steadystate conditions, it is thought that most HSCs reside in the $G_{0}$ phase of the cell cycle in close contact with stromal cells, including osteoblasts (Calvi et al. 2003; Zhang et al. 2003). The balance between quiescent and cycling stem cells appears to rely on the amount of soluble cytokines, which result in HSCs relocating from the osteoblastic to the vascular niche (Heissig et al. 2002). This mobilization of stem cells into peripheral circulation may be necessary for reconstituting the HSC pool. Many signaling pathways are thought to contribute to stem cell self-renewal in the marrow niche including Notch (Maillard et al. 2003), Wnt (Reya et al. 2003; Willert et al. 2003; Duncan et al. 2005), Hedgehog (Baron 2001; Bhardwaj et al. 2001; Gering and Patient 2005), and factors that negatively regulate the cell cycle, such as Tie2/Angiopoietin-1 (Arai et al. 2004). Cooperation of such pathways is thought to maintain stem cell homeostasis in vivo.

Several studies have hypothesized that Notch affects HSCs, although direct proof of the activity and the downstream targets have remained to be elucidated. In murine cell culture, constitutive Notch1 expression in HSC/progenitor cells established immortalized cell lines able to generate progeny with either lymphoid or my- 
eloid characteristics (Varnum-Finney et al. 2000, 2003). Retroviral Notch1 activation in recombination activating gene-1 (RAG-1)-deficient mouse stem cells resulted in an increase in HSC self-renewal and favored lymphoid over myeloid differentiation (Stier et al. 2002).

The studies presented here differ from others in that a brief pulse of Notch activity was administered and the cells were able to terminally differentiate. Other experiments with retroviruses and conditional alleles permanently express NICD and thus alter the normal maturation of cells. For instance, in our adult assays an increase in the lymphoid cell fate was not concomitant with a decrease in the myeloid lineage, as previously seen (Stier et al. 2002). Based on these results, we propose that activated Notch expands the stem and progenitor cell compartment by either influencing undifferentiated cells to adopt a HSC fate or by causing a $\mathrm{G}_{0}$ HSC population to up-regulate runx1-dependent gene expression.

Our findings that the stem cell markers runx1, scl, and Imo2 were transcriptionally increased in response to NICD indicates that stem and progenitor cells were expanded in the adult marrow, possibly by increasing stem cell self-renewal. Recently, a conditional allele of runx1 was generated in the mouse to study the loss of Runx1 function during adult hematopoiesis (Ichikawa et al. 2004; Growney et al. 2005). In transplantation studies, Runx1-excised marrow cells showed a reduced competitive repopulating ability in long-term engraftment assays (Growney et al. 2005), demonstrating that Runxl is essential for normal stem cell function. We demonstrate that the NICD-induced expansion of HSCs in the AGM is dependent on Runxl. When we examined the proximal and distal promoters of the human runx1 gene (Ghozi et al. 1996), we found no DNA-binding sites for RBPjк, the primary Notch pathway mediator that physically interacts with DNA to modulate target gene transcription (Lai 2002a; data not shown). It is still possible that Notch directly regulates runx1 transcription through alternative binding sites, although it may indirectly activate runx1 expression. In either case, the Notch-Runx pathway is likely operative in both the AGM and adult marrow and may lead to the activation of downstream targets critical for stem cell homeostasis.

Notch signaling has been extensively linked to the process of both normal and aberrant stem cell self-renewal (Maillard et al. 2003). The human Notch1 receptor, TAN-1, was first identified as a partner gene in a $(7 ; 9)$ chromosomal translocation found in $<1 \%$ of all T-cell acute lymphoblastic leukemias (T-ALL) (Ellisen et al. 1991). Recently, $>50 \%$ of all human T-ALLs were shown to have activating mutations in the notch1 gene (Weng et al. 2004). These data emphasize how dysregulation of the Notch signaling pathway can result in uncontrolled self-renewal that ultimately produces malignancy.

\section{Clinical implications}

Transplantation of HSCs has been successful in the treatment of malignancies and other diseases, such as aplastic and sickle-cell anemia (Gaziev and Lucarelli
2003). After irradiation or chemotherapy is given to patients, restoration of normal hematopoiesis is critical to prevent infection and bleeding. In this study, we showed that a pulse of Notch activity expands stem cell number in the adult marrow without permanently altering blood lineage homeostasis. This finding has obvious therapeutic implications. Small molecule agonists that induce Notch signaling could be used to pharmacologically expand stem cell numbers and blood progenitors. For instance, embryonic cord blood stem cells are often insufficient for adult stem cell transplants. Notch activators may be used to increase mobilization of HSCs for transplantation, similar to the clinical activity of G-CSF in peripheral stem cell harvests. Our data provide rationale for future clinical work to focus on methods that manipulate the Notch signaling pathway to amplify blood stem cells, and thus multilineage hematopoiesis.

\section{Materials and methods}

\section{Fish care and strains}

Zebrafish were bred and maintained as described (SolnicaKrezel et al. 1994). The following lines were used: wild-type $\mathrm{AB}$, wik, and Tu strains, mind bomb ${ }^{\text {ta56b }}$ (Jiang et al. 1996), Tg(uas:notch1a-intra) (Scheer and Campos-Ortega 1999), and $\mathrm{Tg}($ hsp70:gal4) (Scheer and Campos-Ortega 1999).

\section{In situ hybridization, morpholinos, and mRNAs}

Whole-mount in situ hybridization was performed as described (Thisse et al. 1993). Digoxygenin-labeled antisense RNA probes were synthesized using a DIG RNA Labeling Kit (SP6/T7; Roche). For histological analysis, embryos were embedded in JB4 plastic resin (Polysciences Inc.). Embedded embryos were prepared using a Leica microtome and the resulting $8-10-\mu \mathrm{m}$ sections were mounted onto glass slides and photographed.

The antisense morpholino oligos (Summerton et al. 1997; Ekker 2000; Nasevicius and Ekker 2000) runxMO3 (5'-TGT TAAACTCACGTCGTGGCTCTC-3') and runxMO5 (5'-AAT GTGTAAACTCACAGTGTAAAGC-3') recognize donor sites of predicted exon/intron junctions. The final injection solution contained 0.6 mM runxMO3, 1 mM runxMO5, 1× Danieau Medium, and $1 \times$ Phenol Red (Saude et al. 2000). The mind bomb morpholino (Itoh et al. 2003) was injected at a concentration of $1 \mathrm{mM}$ in $1 \times$ Danieau Medium/1× Phenol Red.

runx1, formerly known as runxa (Burns et al. 2002), was subcloned into the pCS2+ expression vector, and capped RNA was synthesized using mMessage Machine (Ambion). Ten picograms to 20 pg of RNA was injected into the yolk of one-cell- to two-cell-stage embryos.

\section{Immunostaining and BrdU incorporation}

Embryos were fixed overnight in $4 \%$ paraformaldehyde at $4{ }^{\circ} \mathrm{C}$. For staining, embryos were washed twice in PBST, incubated in acetone for $7 \mathrm{~min}$ at $-20^{\circ} \mathrm{C}$, then washed once in water and twice in PBST at room temperature. Embryos were incubated in polyclonal anti-pH3 antibody (1:750 dilution; Santa Cruz Biotechnology) for at least $2 \mathrm{~h}$ at room temperature, washed in PBS- $\mathrm{T}$, incubated in goat anti-rabbit horseradish peroxidaseconjugated antibody (Jackson Immunoresearch) for $2 \mathrm{~h}$ at room 
temperature, washed in PBS-T, and then developed in diaminobenzidine $/ \mathrm{H}_{2} \mathrm{O}_{2}$ (Sigma).

For BrdU incorporation, embryos were chilled on ice for 15 min at the 24- and 40-hpf stages and pulsed in a $10 \mathrm{mM} \mathrm{BrdU}$, $15 \%$ DMSO solution for $20 \mathrm{~min}$ on ice. Embryos were then transferred to warm embryo media, incubated for $5 \mathrm{~min}$ at $28.5^{\circ} \mathrm{C}$, fixed in $4 \%$ PFA for $2 \mathrm{~h}$ at room temperature, and incubated overnight in methanol at $-20^{\circ} \mathrm{C}$. Embryos were rehydrated in PBS-T, digested with proteinase $\mathrm{K}(10 \mu \mathrm{g} / \mathrm{mL})$, and post-fixed in 4\% PFA for $20 \mathrm{~min}$ at room temperature. Embryos were washed in $\mathrm{H}_{2} \mathrm{O}$, incubated in $2 \mathrm{~N} \mathrm{HCl}$ for $1 \mathrm{~h}$, washed in PBS-T, and placed in a blocking solution for $30 \mathrm{~min}$ at room temperature. Embryos were incubated in monoclonal anti-BrdU antibody (1:100 dilution; Sigma) for at least $2 \mathrm{~h}$ at room temperature, incubated in goat anti-mouse horseradish peroxidaseconjugated antibody (Jackson Immunoresearch) for $2 \mathrm{~h}$ at room temperature, washed in PBS-T, and then developed in diaminobenzidine $/ \mathrm{H}_{2} \mathrm{O}_{2}$ (Sigma).

\section{Embryo heat-shock experiments}

$\operatorname{Tg}($ hsp 70:gal4) adults were mated to $\mathrm{Tg}$ (uas:notch1a-intra) fish and their embryos were harvested and raised in E3 (Westerfield 1995). Between the 8- and 12-somite stages, embryos were collected in 50-mL Falcon tubes in $\sim 5 \mathrm{~mL}$ of $\mathrm{E} 3$ and submerged in a $37^{\circ} \mathrm{C}$ waterbath for $30-45 \mathrm{~min}$. Subsequently, embryos were placed in Petri dishes, allowed to develop until $\sim 40 \mathrm{hpf}$, collected in $4 \%$ paraformaldehyde, and processed by in situ hybridization. For the results in Figure 3, the experimental conditions for timing and heat shock were followed from Lawson et al. (2002).

\section{Adult irradiation, heat shock, and kinetic analysis}

$\operatorname{Tg}($ hsp 70:gal4) adults were mated to $\operatorname{Tg}$ (uas:notch1a-intra) fish and their embryos were harvested and raised. Genomic DNA was extracted from clipped tail fins, and PCR amplification determined whether each transgene was present. Control siblings (wild type or single transgenics) and experimental hsp70:gal4; uas:NICD double transgenic fish were irradiated at a sublethal dose of $2000 \mathrm{rads} / 20$ Gy (day 0), as previously described (Traver et al. 2004). Fish were returned to the aquatics facility until day 2, when they were removed and placed in a $37^{\circ} \mathrm{C}$ dry incubator overnight. The fish were returned to the aquatics facility on day 3.

Whole kidney marrow was dissected from the following number of euthanized adult zebrafish: day 0, wild type $=3$, hsp70:gal4; uas:NICD (TG) = 3; day 2, wild type $=4, \mathrm{TG}=3$; day 4, wild type $=6, \mathrm{TG}=6$; day 7 , wild type $=6, \mathrm{TG}=7$; day 8 , wild type $=4, \mathrm{TG}=4$; day 10 , wild type $=5, \mathrm{TG}=4$; day 15 , wild type $=5, \mathrm{TG}=4$; day 30, wild type $=5, \mathrm{TG}=3$. Individual kidneys were placed in a 12 -well Petri plate on ice in $2 \mathrm{~mL}$ of ice-cold $0.9 \times$ Dulbecco's phosphate buffered saline (PBS) containing $5 \% \quad 0.2-\mu \mathrm{m}$-filtered fetal calf serum (FCS). The kidney was dissociated to a single cell suspension by repeated pipetting with a P1000. The suspension was then filtered over a $40-\mu \mathrm{m}$ nylon mesh into a FACS tube on ice. The 2-mL suspension was then aliquoted to $1 \mathrm{~mL}$ per FACS tube. One-hundred-thousand cells were collected by flow cytometry based on propidium iodide (PI) exclusion (1 $\mu \mathrm{g} / \mathrm{mL}$; Sigma), forward scatter, and side scatter using a FACS Vantage flow cytometer (Becton Dickinson), as previously described (Traver et al. 2004). Total kidney cell counts were performed using a hemocytometer.

\section{Quantitative PCR analysis from whole kidney marrow}

Adult fish were sublethally irradiated and heat-shocked as described above. Fish were removed from the $37^{\circ} \mathrm{C}$ incubator on day 3 and kept at room temperature for $3-4$ h, at which time individual kidneys were dissected. Each kidney was placed in Trizol (Invitrogen), total RNA was isolated, and random primed cDNA was generated (Invitrogen, SuperScript III First-Strand Synthesis System). The SYBR green (Invitrogen) method was used to quantify cDNAs of interest, which are represented as the fold change in transcript level between control sibling and hsp70:gal4;uas:NICD kidneys. The amount of cDNA starting material for each kidney was normalized in relation to $\beta$-actin expression. For all experiments, cDNA was quantified using an Applied Biosystems Sequence Detection System 7000. The primer sequences used were as follows: scl: forward, $5^{\prime}$-CTC GAATGGTGCAGTTGAGTCC-3', reverse, 5'-GCATCTCCAG CAAAACCACTGT-3'; flk1: forward, 5'-CGAACGTGAAGT GACATACGG-3', reverse, 5'-CCCTCTACCAAACCATGTGA AA-3'; fli1: forward, 5'-CCCCTCAGCAAGAGTGGATTA-3', reverse, 5'-CGGCGACTCTTGTGCAGTATAT-3'; runx1: forward, 5' ${ }^{\prime}$-CGTCTTCACAAACCCTCCTCAA- ${ }^{\prime}$ ', reverse, $5^{\prime}$-GC TTTACTGCTTCATCCGGCT-3'; Imo2: forward, 5' -AAACAC TGGAGGCAAATGAGGA-3' ${ }^{\prime}$, reverse, 5' $^{\prime}$-AGAAAGAAGCGG TCTCCGATG-3'; gata2: forward, 5'-ACAACGTCAACAGGC CACTGA-3', reverse, 5' -TCGAAACCCTCACCAGATCGT-3'; ß-actin: forward, 5'-GCTGTTTTCCCCTCCATTGTT-3', re-

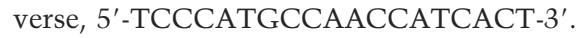

\section{Acknowledgments}

We thank S. Orkin, G. Daley, and W. Goessling for critical evaluation of the manuscript; C. Belair and B. Barut for animal and laboratory management; A. Flint for assistance with flow cytometry; R. Peterson for $\beta$-actin quantitative PCR primers; and B. Appel and A. Latimer for mind bomb mutant lines. C.E.B. was supported by the American Cancer Society (PF-01255-01-LIB) and currently holds a Research Career Award (1 K01 DK067179-01 A1) through the NIH NIDDK division. L.I.Z. is supported by HHMI, and this work was funded by a grant from the NIH NHLBI (5 R01 HL48801-13).

\section{References}

Arai, F., Hirao, A., Ohmura, M., Sato, H., Matsuoka, S., Takubo, K., Ito, K., Koh, G.Y., and Suda, T. 2004. Tie2/angiopoietin-1 signaling regulates hematopoietic stem cell quiescence in the bone marrow niche. Cell 118: 149-161.

Avecilla, S.T., Hattori, K., Heissig, B., Tejada, R., Liao, F., Shido, K., Jin, D.K., Dias, S., Zhang, F., Hartman, T.E., et al. 2004. Chemokine-mediated interaction of hematopoietic progenitors with the bone marrow vascular niche is required for thrombopoiesis. Nat. Med. 10: 64-71.

Baron, M. 2001. Induction of embryonic hematopoietic and endothelial stem/progenitor cells by hedgehog-mediated signals. Differentiation 68: 175-185.

Bhardwaj, G., Murdoch, B., Wu, D., Baker, D.P., Williams, K.P., Chadwick, K., Ling, L.E., Karanu, F.N., and Bhatia, M. 2001. Sonic hedgehog induces the proliferation of primitive human hematopoietic cells via BMP regulation. Nat. Immunol. 2: $172-180$.

Bray, S. 1998. Notch signalling in Drosophila: Three ways to use a pathway. Semin. Cell Dev. Biol. 9: 591-597.

Burns, C.E., DeBlasio, T., Zhou, Y., Zhang, J., Zon, L., and Nimer, S.D. 2002. Isolation and characterization of runxa and runxb, zebrafish members of the runt family of transcriptional regulators. Exp. Hematol. 30: 1381-1389.

Calvi, L.M., Adams, G.B., Weibrecht, K.W., Weber, J.M., Olson, 
D.P., Knight, M.C., Martin, R.P., Schipani, E., Divieti, P., Bringhurst, F.R., et al. 2003. Osteoblastic cells regulate the haematopoietic stem cell niche. Nature 425: 841-846.

Chen, W. and Casey Corliss, D. 2004. Three modules of zebrafish Mind bomb work cooperatively to promote Delta ubiquitination and endocytosis. Dev. Biol. 267: 361-373.

Cossu, G. and Bianco, P. 2003. Mesoangioblasts-Vascular progenitors for extravascular mesodermal tissues. Curr. Opin. Genet. Dev. 13: 537-542.

Deblandre, G.A., Lai, E.C., and Kintner, C. 2001. Xenopus neuralized is a ubiquitin ligase that interacts with XDeltal and regulates Notch signaling. Dev. Cell 1: 795-806.

Duncan, A.W., Rattis, F.M., Dimascio, L.N., Congdon, K.L., Pazianos, G., Zhao, C., Yoon, K., Cook, J.M., Willert, K., Gaiano, N., et al. 2005. Integration of Notch and Wnt signaling in hematopoietic stem cell maintenance. Nat. Immunol. 6: 314-322.

Durand, C. and Dzierzak, E. 2005. Embryonic beginnings of adult hematopoietic stem cells. Haematologica 90: 100-108.

Ekker, S.C. 2000. Morphants: A new systematic vertebrate functional genomics approach. Yeast 17: 302-306.

Ellisen, L.W., Bird, J., West, D.C., Soreng, A.L., Reynolds, T.C., Smith, S.D., and Sklar, J. 1991. TAN-1, the human homolog of the Drosophila notch gene, is broken by chromosomal translocations in T lymphoblastic neoplasms. Cell 66: 649661.

Ema, M., Faloon, P., Zhang, W.J., Hirashima, M., Reid, T., Stanford, W.L., Orkin, S., Choi, K., and Rossant, J. 2003. Combinatorial effects of Flk1 and Tall on vascular and hematopoietic development in the mouse. Genes \& Dev. 17: 380-393.

Fujita, Y., Nishimura, M., Taniwaki, M., Abe, T., and Okuda, T. 2001. Identification of an alternatively spliced form of the mouse AML1/RUNX1 gene transcript AML1c and its expression in early hematopoietic development. Biochem. Biophys. Res. Commun. 281: 1248-1255.

Gaziev, J. and Lucarelli, G. 2003. Stem cell transplantation for hemoglobinopathies. Curr. Opin. Pediatr. 15: 24-31.

Gering, M. and Patient, R. 2005. Hedgehog signaling is required for adult blood stem cell formation in zebrafish embryos. Dev. Cell 8: 389-400.

Ghozi, M.C., Bernstein, Y., Negreanu, V., Levanon, D., and Groner, Y. 1996. Expression of the human acute myeloid leukemia gene AML1 is regulated by two promoter regions. Proc. Natl. Acad. Sci. 93: 1935-1940.

Golling, G., Amsterdam, A., Sun, Z., Antonelli, M., Maldonado, E., Chen, W., Burgess, S., Haldi, M., Artzt, K., Farrington, S., et al. 2002. Insertional mutagenesis in zebrafish rapidly identifies genes essential for early vertebrate development. Nat. Genet. 31: 135-140.

Greenwald, I. and Rubin, G.M. 1992. Making a difference: The role of cell-cell interactions in establishing separate identities for equivalent cells. Cell 68: 271-281.

Growney, J.D., Shigematsu, H., Li, Z., Lee, B.H., Adelsperger, J., Rowan, R., Curley, D.P., Kutok, J.L., Akashi, K., Williams, I.R., et al. 2005. Loss of Runxl perturbs adult hematopoiesis and is associated with a myeloproliferative phenotype. Blood 106: 494-504.

Hadland, B.K., Huppert, S.S., Kanungo, J., Xue, Y., Jiang, R., Gridley, T., Conlon, R.A., Cheng, A.M., Kopan, R., and Longmore, G.D. 2004. A requirement for Notch1 distinguishes 2 phases of definitive hematopoiesis during development. Blood 104: 3097-3105.

Haffter, P., Granato, M., Brand, M., Mullins, M.C., Hammerschmidt, M., Kane, D.A., Odenthal, J., van Eeden, F.J., Jiang, Y.J., Heisenberg, C.P., et al. 1996. The identification of genes with unique and essential functions in the development of the zebrafish, Danio rerio. Development 123: 1-36.

Halloran, M.C., Sato-Maeda, M., Warren, J.T., Su, F., Lele, Z., Krone, P.H., Kuwada, J.Y., and Shoji, W. 2000. Laser-induced gene expression in specific cells of transgenic zebrafish. Development 127: 1953-1960.

Heissig, B., Hattori, K., Dias, S., Friedrich, M., Ferris, B., Hackett, N.R., Crystal, R.G., Besmer, P., Lyden, D., Moore, M.A., et al. 2002. Recruitment of stem and progenitor cells from the bone marrow niche requires MMP-9 mediated release of kit-ligand. Cell 109: 625-637.

Ichikawa, M., Asai, T., Chiba, S., Kurokawa, M., and Ogawa, S. 2004. Runx1/AML-1 ranks as a master regulator of adult hematopoiesis. Cell Cycle 3: 722-724.

Itoh, M., Kim, C.H., Palardy, G., Oda, T., Jiang, Y.J., Maust, D., Yeo, S.Y., Lorick, K., Wright, G.J., Ariza-McNaughton, L., et al. 2003. Mind bomb is a ubiquitin ligase that is essential for efficient activation of Notch signaling by Delta. Dev. Cell 4: $67-82$.

Jiang, Y.J., Brand, M., Heisenberg, C.P., Beuchle, D., FurutaniSeiki, M., Kelsh, R.N., Warga, R.M., Granato, M., Haffter, P., Hammerschmidt, M., et al. 1996. Mutations affecting neurogenesis and brain morphology in the zebrafish, Danio rerio. Development 123: 205-216.

Kalev-Zylinska, M.L., Horsfield, J.A., Flores, M.V., Postlethwait, J.H., Vitas, M.R., Baas, A.M., Crosier, P.S., and Crosier, K.E. 2002. Runx1 is required for zebrafish blood and vessel development and expression of a human RUNX1-CBF2T1 transgene advances a model for studies of leukemogenesis. Development 129: 2015-2030.

Kumano, K., Chiba, S., Kunisato, A., Sata, M., Saito, T., Nakagami-Yamaguchi, E., Yamaguchi, T., Masuda, S., Shimizu, K., Takahasi, T., et al. 2003. Notch1 but Not Notch2 is essential for generating hematopoietic stem cells from endothelial cells. Immunity 18: 699-711.

Kunisato, A., Chiba, S., Nakagami-Yamaguchi, E., Kumano, K., Saito, T., Masuda, S., Yamaguchi, T., Osawa, M., Kageyama, R., Nakauchi, H., et al. 2003. HES-1 preserves purified hematopoietic stem cells ex vivo and accumulates side population cells in vivo. Blood 101: 1777-1783.

Lai, E.C. 2002a. Keeping a good pathway down: Transcriptional repression of Notch pathway target genes by CSL proteins. EMBO Rep. 3: 840-845.

. 2002b. Protein degradation: Four E3s for the notch pathway. Curr. Biol. 12: R74-R78.

Lai, E.C., Deblandre, G.A., Kintner, C., and Rubin, G.M. 2001. Drosophila neuralized is a ubiquitin ligase that promotes the internalization and degradation of delta. Dev. Cell 1: $783-$ 794.

Lawson, N.D., Scheer, N., Pham, V.N., Kim, C.H., Chitnis, A.B., Campos-Ortega, J.A., and Weinstein, B.M. 2001. Notch signaling is required for arterial-venous differentiation during embryonic vascular development. Development 128: 36753683.

Lawson, N.D., Vogel, A.M., and Weinstein, B.M. 2002. sonic hedgehog and vascular endothelial growth factor act upstream of the Notch pathway during arterial endothelial differentiation. Dev. Cell 3: 127-136.

Le Borgne, R. and Schweisguth, F. 2003. Notch signaling: Endocytosis makes delta signal better. Curr. Biol. 13: R273-R275.

Lewis, J. 1998. Notch signalling and the control of cell fate choices in vertebrates. Semin. Cell Dev. Biol. 9: 583-589.

Maillard, I., Adler, S.H., and Pear, W.S. 2003. Notch and the immune system. Immunity 19: 781-791.

Mandal, L., Banerjee, U., and Hartenstein, V. 2004. Evidence for a fruit fly hemangioblast and similarities between lymphgland hematopoiesis in fruit fly and mammal aorta-gonadal- 
mesonephros mesoderm. Nat. Genet. 36: 1019-1023.

Mendes, S.C., Robin, C., and Dzierzak, E. 2005. Mesenchymal progenitor cells localize within hematopoietic sites throughout ontogeny. Development 132: 1127-1136.

Nasevicius, A. and Ekker, S.C. 2000. Effective targeted gene 'knockdown' in zebrafish. Nat. Genet. 26: 216-220.

Ohishi, K., Katayama, N., Shiku, H., Varnum-Finney, B., and Bernstein, I.D. 2003. Notch signalling in hematopoiesis. Semin. Cell Dev. Biol. 14: 143-150.

Okuda, T., Nishimura, M., Nakao, M., and Fujita, Y. 2001. RUNX1/AML1: A central player in hematopoiesis. Int. J. Hematol. 74: 252-257.

Pavlopoulos, E., Pitsouli, C., Klueg, K.M., Muskavitch, M.A., Moschonas, N.K., and Delidakis, C. 2001. neuralized encodes a peripheral membrane protein involved in delta signaling and endocytosis. Dev. Cell 1: 807-816.

Pui, J.C., Allman, D., Xu, L., DeRocco, S., Karnell, F.G., Bakkour, S., Lee, J.Y., Kadesch, T., Hardy, R.R., Aster, J.C., et al. 1999. Notch1 expression in early lymphopoiesis influences $\mathrm{B}$ versus T lineage determination. Immunity 11: 299-308.

Radtke, F., Wilson, A., Stark, G., Bauer, M., van Meerwijk, J., MacDonald, H.R., and Aguet, M. 1999. Deficient T cell fate specification in mice with an induced inactivation of Notch1. Immunity 10: 547-558.

Reya, T., Duncan, A.W., Ailles, L., Domen, J., Scherer, D.C., Willert, K., Hintz, L., Nusse, R., and Weissman, I.L. 2003. A role for Wnt signalling in self-renewal of haematopoietic stem cells. Nature 423: 409-414.

Robert-Moreno, A., Espinosa, L., de la Pompa, J.L., and Bigas, A. 2005. RВPјк-dependent Notch function regulates Gata2 and is essential for the formation of intra-embryonic hematopoietic cells. Development 132: 1117-1126.

Robey, E., Chang, D., Itano, A., Cado, D., Alexander, H., Lans, D., Weinmaster, G., and Salmon, P. 1996. An activated form of Notch influences the choice between CD4 and CD8 T cell lineages. Cell 87: 483-492.

Saude, L., Woolley, K., Martin, P., Driever, W., and Stemple, D.L. 2000. Axis-inducing activities and cell fates of the zebrafish organizer. Development 127: 3407-3417.

Scheer, N. and Campos-Ortega, J.A. 1999. Use of the Gal4-UAS technique for targeted gene expression in the zebrafish. Mech. Dev. 80: 153-158.

Scheer, N., Riedl, I., Warren, J.T., Kuwada, J.Y., and CamposOrtega, J.A. 2002. A quantitative analysis of the kinetics of Gal4 activator and effector gene expression in the zebrafish. Mech. Dev. 112: 9-14.

Schier, A.F., Neuhauss, S.C., Harvey, M., Malicki, J., SolnicaKrezel, L., Stainier, D.Y., Zwartkruis, F., Abdelilah, S., Stemple, D.L., Rangini, Z., et al. 1996. Mutations affecting the development of the embryonic zebrafish brain. Development 123: 165-178.

Solnica-Krezel, L., Schier, A.F., and Driever, W. 1994. Efficient recovery of ENU-induced mutations from the zebrafish germline. Genetics 136: 1401-1420.

Stier, S., Cheng, T., Dombkowski, D., Carlesso, N., and Scadden, D.T. 2002. Notch1 activation increases hematopoietic stem cell self-renewal in vivo and favors lymphoid over myeloid lineage outcome. Blood 99: 2369-2378.

Summerton, J., Stein, D., Huang, S.B., Matthews, P., Weller, D., and Partridge, M. 1997. Morpholino and phosphorothioate antisense oligomers compared in cell-free and in-cell systems. Antisense Nucleic Acid Drug Dev. 7: 63-70.

Thisse, C., Thisse, B., Schilling, T.F., and Postlethwait, J.H. 1993. Structure of the zebrafish snaill gene and its expression in wild-type, spadetail and no tail mutant embryos. Development 119: 1203-1215.
Traver, D. and Zon, L.I. 2002. Walking the walk: Migration and other common themes in blood and vascular development. Cell 108: 731-734.

Traver, D., Paw, B.H., Poss, K.D., Penberthy, W.T., Lin, S., and Zon, L.I. 2003. Transplantation and in vivo imaging of multilineage engraftment in zebrafish bloodless mutants. Nat. Immunol. 4: 1238-1246.

Traver, D., Winzeler, A., Stern, H.M., Mayhall, E.A., Langenau, D.M., Kutok, J.L., Look, A.T., and Zon, L.I. 2004. Effects of lethal irradiation in zebrafish and rescue by hematopoietic cell transplantation. Blood 104: 1298-1305.

Varnum-Finney, B., Xu, L., Brashem-Stein, C., Nourigat, C., Flowers, D., Bakkour, S., Pear, W.S., and Bernstein, I.D. 2000. Pluripotent, cytokine-dependent, hematopoietic stem cells are immortalized by constitutive Notch1 signaling. Nat. Med. 6: 1278-1281.

Varnum-Finney, B., Brashem-Stein, C., and Bernstein, I.D. 2003. Combined effects of Notch signaling and cytokines induce a multiple log increase in precursors with lymphoid and myeloid reconstituting ability. Blood 101: 1784-1789.

Wang, Q., Stacy, T., Binder, M., Marin-Padilla, M., Sharpe, A.H., and Speck, N.A. 1996. Disruption of the Cbfa2 gene causes necrosis and hemorrhaging in the central nervous system and blocks definitive hematopoiesis. Proc. Nat1. Acad. Sci. 93: 3444-3449.

Washburn, T., Schweighoffer, E., Gridley, T., Chang, D., Fowlkes, B.J., Cado, D., and Robey, E. 1997. Notch activity influences the $\alpha \beta$ versus $\gamma \delta \mathrm{T}$ cell lineage decision. Cell 88: 833-843.

Weng, A.P., Ferrando, A.A., Lee, W., Morris, J.P.T., Silverman, L.B., Sanchez-Irizarry, C., Blacklow, S.C., Look, A.T., and Aster, J.C. 2004. Activating mutations of NOTCH1 in human T cell acute lymphoblastic leukemia. Science 306: 269271.

Westerfield, M. 1995. The zebrafish book, 3rd ed. University of Oregon Press, Eugene, OR.

Willert, K., Brown, J.D., Danenberg, E., Duncan, A.W., Weissman, I.L., Reya, T., Yates III, J.R., and Nusse, R. 2003. Wnt proteins are lipid-modified and can act as stem cell growth factors. Nature 423: 448-452.

Yeh, E., Dermer, M., Commisso, C., Zhou, L., McGlade, C.J., and Boulianne, G.L. 2001. Neuralized functions as an E3 ubiquitin ligase during Drosophila development. Curr. Biol. 11: 1675-1679.

You, L.R., Lin, F.J., Lee, C.T., DeMayo, F.J., Tsai, M.J., and Tsai, S.Y. 2005. Suppression of Notch signalling by the COUPTFII transcription factor regulates vein identity. Nature 435: 98-104.

Zhang, J., Niu, C., Ye, L., Huang, H., He, X., Tong, W.G., Ross, J., Haug, J., Johnson, T., Feng, J.Q., et al. 2003. Identification of the haematopoietic stem cell niche and control of the niche size. Nature 425: 836-841. 


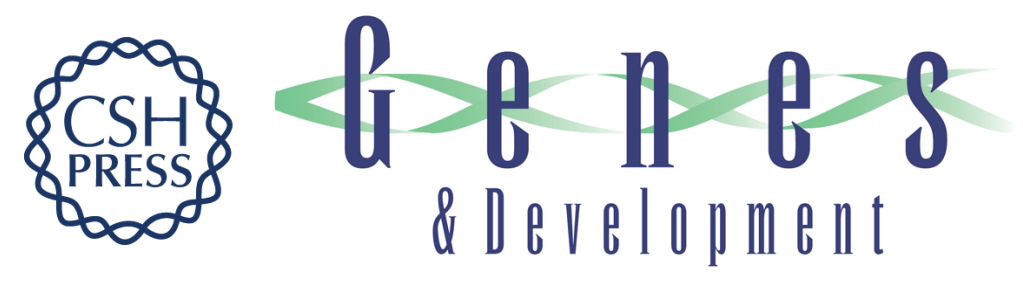

\section{Hematopoietic stem cell fate is established by the Notch-Runx pathway}

Caroline Erter Burns, David Traver, Elizabeth Mayhall, et al.

Genes Dev. 2005, 19:

Access the most recent version at doi:10.1101/gad.1337005

\section{Supplemental http://genesdev.cshlp.org/content/suppl/2005/09/15/gad.1337005.DC1 Material}

References This article cites 70 articles, 22 of which can be accessed free at: http://genesdev.cshlp.org/content/19/19/2331.full.html\#ref-list-1

\section{License}

Email Alerting

Receive free email alerts when new articles cite this article - sign up in the box at the top Service 